\section{Effects of a reduction in reward magnitude on active avoidance behavior in humans}

\author{
LAWRENCE WEINSTEIN* \\ University of Melbourne, Melbourne, Austraiia
}

Human Ss actively avoided a tone previously paired with a decrease in monetary incentive magnitude and consequent negative contrast effects more often than did individuals the tone associated with the control group's lower quantity of reward. These data agree with the notion that at the human level, negative incentive contrast effects are explainable in terms of an aversive motivation response.

Downward negative incentive contrast effects in which a reduction in incentive size results in a reliably lower level of performance than the level of behavior of a control group maintained on the lower incentive magnitude throughout training have not only been demonstrated with animals in a variety of situations with a number of different reinforcing agents (Black, 1968; Dunham, 1968), but there is also a considerable body of evidence which suggests that the phenomenon is accounted for by an aversive motivational state such as frustration or fear (e.g., Brown \& Murphy, 1970; Capaldi \& Lynch, 1967; Mikulka, Lehr, \& Pavlik, 1967; Rosen, Glass, \& Ison, 1967 ; Rosen \& Tessel, 1970).

At the human level, negative contrast has been only recently demonstrated (e.g., Weinstein, 1970 Weinstein \& Colucci, 1970) with information available concerning the determinants of the phenomenon. The present experiment examined the notion that downward contrast effects in human behavior are accounted for by an aversive motivational response.

According to such an emotional-motivational explanation of negative contrast effects in humans, a decrease in incentive magnitude results in some aversive motivational response, which produces a variety of internal stimuli which elicit responses that compete with instrumental performance so that behavior is significantly impaired (Amsel, 1958, $1960 ;$ Spence, 1956, 1960). If downward contrast effects in humans are due to emotional factors, one might expect a neutral stimulus when paired with a reduction in reward quantity, which produces negative contrast, to become aversive and result in more active avoidance than when the cue is associated with the control group's smaller amount of reinforcement. In other words, if a neutral event when associated with

* Requests for reprints should be sent to Lawrence Weinstein. c/o John Babchuk. Box 308. Willingdon, Alberta. $C$ anada. downward contrast effects consequently produces more active avoidance than a stimulus paired with the control Ss' lower quantity of reward, these findings would be consonant with the notion that a decrease in quantity of reinforcement with human Ss has aversive emotional consequences which account for negative incentive contrast effects.

The present investigation examined the effects of an auditory stimulus paired with a reduction in incentive magnitude, as compared to when the cue is associated with the control group's lower magnitude of reward on active avoidance behavior in human Ss. SUBJECTS

The Ss were 20 males and 20 females enrolled in an introductory Oklahoma. The Ss were assigned randomly to each of five groups so that four males and four females appeared in each group.

\section{APPARATUS}

The materials consisted of a Kodak Carousel 750 slide projector, $139.7 \mathrm{~mm}$ from a $152.4-\mathrm{mm}$-square piece of cardboard that served as a screen, $50.8 \times 42.6 \mathrm{~mm}$ slides with digits typed on them (i.e., $126 \times 4$ ), and a stopwatch. The auditory signal, a $1,000-\mathrm{Hz} 70-\mathrm{dB}$ SPL tone produced by an audio oscillator, was presented through a speaker placed $.3048 \mathrm{~m}$ directly behind the S's head. The onset of the 3-sec tone in the postshift was manually controlled by $\mathrm{E}$.

The active avoidance apparatus consisted of a panel, .0929 m square, with a button (response key) in the center and a 25-W light (conditioned stimulus) $50.8 \mathrm{~mm}$ above the button. The same tone used in the postshift was used as the unconditioned stimulus, $.3048 \mathrm{~m}$ directly behind S's head. The durations of the light and tone, $10 \mathrm{sec}$ and $60 \mathrm{sec}$, respectively, were manually controlled by $\mathrm{E}$.

\section{PROCEDURE}

Each $S$ worked the same sequence of the same mental multiplication problems. One correct or incorrect answer, or $60 \mathrm{sec}$, whichever came first, was allowed for each problem, with 4 sec between problems. psychology course at the University of
The problems were worked in five situations. In one group (1-1), Ss received 1 cent after correctly or incorrectly answering Problems $2,3,4$, $6,11,14,15,18,23,24,25,26$, and 28. Another group (25-1) received 25 cents through Problem 14 and then continually received 1 cent on the designated trials. In a third condition (1-1T), individuals received 1 cent through Problem 14, followed by 1 cent plus the $3 \mathrm{sec}$ tone on Problems $15,18,23,24,25,26$, and 28. Some Ss $(25-1 \mathrm{~T})$ received 25 cents for 14 problems, followed by 1 cent plus the tone for the remainder of the session on the designated trials. Finally, some individuals $(\mathrm{N})$ experienced no reward or tore throughout the preshift.

The Ss were read the following instructions: "This is an experiment in abstract problem solving, the ability to rapidly work problems involving abstract reasoning. You will be given some problems to work. Each one consists of a three-digit number multiplied by a one-digit number. You are, without pencil and paper, in your head, to multiply the numbers as quickly as you can and tell me your answer. You will receive money after some answers. The speed, and accuracy, with which you respond, relative to other Ss, will earn you more money. In other words, you are being rated against other Ss." The E, seated beside the $S$, manually administered the quarter and penny rewards, the tone, operated the slide projector, and recorded latencies with a stopwatch. When $E$ handed $S$ a coin in the postshift, the tone was sounded.

After Problem 30, the 25-1T and $1.1 \mathrm{~T}$ Ss received a $5-\mathrm{min}$ rest period, followed by 30 conditioning trials with the active avoidance apparatus with a constant 60-sec intertrial interval. The $\mathrm{S}$ was seated in front of the panel with the speaker behind his

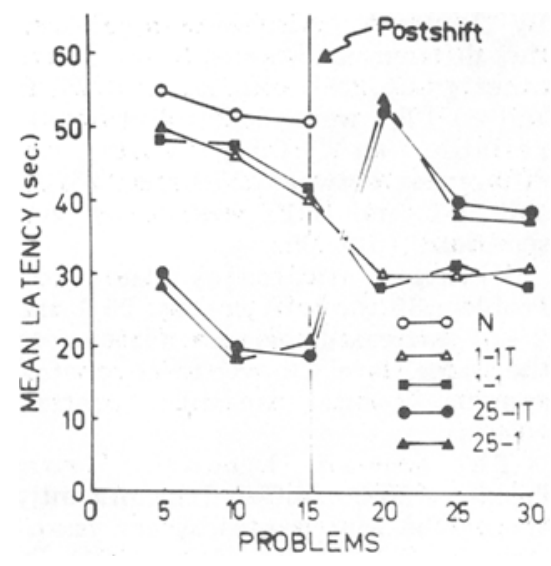

Fig. 1. Mean latency in seconds. Arrow denotes postshift. Data are presented in blocks of five trials. 
head. The E was seated beside S. Sixty seconds after the instructions were read, the light was activated. Ten seconds after light onset, the postshift tone was given until $\mathrm{S}$ pressed the button or until $60 \mathrm{sec}$ elapsed, whichever came first. If $S$ pressed the button before tone onset, the light was discontinued, no tone was given, and an avoidance was scored for the trial. If $S$ pressed the key in the intertrial interval, the time between tone offset and light onset or between avoidance response and light onset and avoidance was not scored, and the $S$ had to avoid or escape at the start of the trial. Responses were manually recorded by $E$. The 25-1T and 1-1T Ss were read the following instructions: "This part of the experiment is concerned with decision-making processes, the ability to make up one's mind as to what shall be done and the way to do it. You will receive a series of lights. When the light is on, a tone will shortly occur. If you press the button in front of you during the light, the tone will be avoided, will not occur; if you do not press the button when the light is on, the tone will occur. Either case will be followed by the light and the same sequence of events. If you do not avoid the tone, you can terminate it once it starts by pressing the button." RESULTS

Latency means (the time between slide onset and the first correct or incorrect answer) were examined in the analysis of the pre- and postshift results.

From Fig. 1 it would appear that the $\mathrm{N}$ individuals reacted more slowly than all other groups, 25-1 and 25-1T each responded faster than their control groups, 1-1 and 1-1T, respectively, 1-1 responded as fast as 1-1T, and, finally, 25-1 reacted as quickly as $25-1 \mathrm{~T}$.

The mean latency from Problems 1-14 differed significantly among the five groups by an analysis of variance, $\mathrm{F}(4,35)=3.12, \mathrm{p}<.05$. By Duncan's multiple comparisons, the differences between $N$ and each other group, 25-1 and 1-1, and 25-1T and $1-1 \mathrm{~T}$, were each statistically reliable $(p<.05)$, while the differences between 25-1 and 25-1T, and 1-1 and 1-1T were each not significant $(p>.05)$.

Figure 1 indicates that on Problem 30 the shift groups, 25-1 and 25-1T, increased their mean latency to the same level above their control groups (equal negative contrast effects)

The mean latency from Problems 20-30 differed significantly among the four groups by analysis of variance, $F(3,36)=5.21$, $p<.01$. By Duncan's comparisons, the differences between 25-1 and 1-1, and 25-1T and



as a function of experimental, 25-1 $\mathrm{T}$, and control, 1-1T, group.

\section{1-1T were each highly reliable} $(p<.01)$, while the difference between the shift groups and control groups were each not significant.

The mean percentage of avoidances in the 30-trial session (number of a voidance responses $/ 30 \times 100$ ) was one response measure examined in the analysis of the active avoidance results.

Figure 2 displays mean percentage avoidances as a function of shift-control group. Examination of Fig. 2 indicates that $S s$ who received the tone paired with a reduction in reward quantity avoided the signal more than did $S s$ in the control condition. Analysis of variance revealed a significant difference between the two groups, $\mathrm{F}(1,14)=19.71, \mathrm{p}<.01$.

Another measure examined in the analysis of the avoidance data was the mean latency of the first avoidance response in the 30 -trial session. This measure yielded effects similar to the percentage avoidances. That is to say, 25-1T took less time to emit the first avoidance response in the session than the 1-1T individuals. The mean latency of the first avoidance response per session differed significantly between the two groups by an analysis of variance, $F(1,14)=5.23, p<.05$.

$$
\text { DISCUSSION }
$$

The present results indicate that human Ss actively avoid a tone previously paired with a reduction in incentive magnitude and consequent negative incentive contrast effects more often than individuals avoid a tone previously associated with the control group's lower magnitude of reinforcement. As already discussed, these findings are consonant with the notion that negative incentive contrast effects at the human level are due to some form of aversive motivational state.
The findings for Problems 1-14 are that: (1) the $\mathrm{N}$ group took significantly more time to respond than any other group, and (2) response latency was a negative function of the magnitude of reward for both tone and no-tone conditions. These findings indicate that: (1) administering 1 and 25 cents after an answer served as reinforcing events, and (2) levels of reward, 1 and 25 cents, were discriminably different where different quantities of incentive are defined in terms of the significantly different levels of performance they produce.

The demonstration of negative incentive contrast effects is consistent with most studies which have reduced incentive size with infrahuman organisms (e.g., Black, 1968); the present results are also in accord with the few demonstrations of negative contrast with human Ss (e.g., Weinstein, 1970; Weinstein \& Colucci, 1970).

AMSEL, A. The role of frustrative nonreward in noncontinuous situations. Psychological Bulletin, 1958, 55, 102-119.

AMSEL, A. Frustrative nonreward in partial reinforcement and discrimination learning: Some recent history and a theoretical extension. Psychological Review, 1962, 69, 306-329.

$B L A C K$, $R$. W. Shifts- in magnitude of reward and effects in instrumental and selective learning: A reinterpretation. Psychological Review, 1968, 75, 114-126.

BROWN T. S. \& MURPHY, H. M. Hippocampal lesions, and incentive shift. Paper presented at the meeting of the E astern Psychological Association, Atlantic City, 1970.

CAPALDI E J \& LYNCH, D. Repeated shifts in reward magnitude: Evidence in favor of an associational and absolute (noncontextual) interpretation. Journal of Experimental Psychology, 1967, 75, 223-235.

DUNHAM, P. J. Contrasted conditions of reinforcement: A selective critique. Psychological Bulletin, 1968, 69, 295-315.

MIKULKA, P. J., LEHR, R., \& PAVLIK, W. B. Effect of reinforcement schedule on reward shifts. Journal of Experimental Psychology, 1967, 74, 57-61.

ROSEN, A. J.. GLASS, D. H., \& ISON, J. R. Amobarbital sodium and instrumental performance changes following reward reduction. Psychonomic Science, 1967, 9, 129-130.

ROSEN, A. J., \& TESSEL, R. E. Chlorpromazine, chlordiazepoxide and incentive shift performance in the rat. Journal of Comparative \& Physiological Psychology, 1970, 72, 257-262.

SPENCE, K. W. Behavior theory and conditioning. New Haven, Conn: Yale University Press, 1956. Pp. 127-137.

SPENCE, $K$. W. The roles of reinforcement and nonreinforcement in simple learningIn Behavior theory and learning. Englewood Cliffs, N.J: Prentice-Hall, 1960.

WEINSTEIN, L. Magnitude of incentive contrast as a function of amount of verbal reward change. Psychonomic Science, 1970, 21, 65-66.

WEINSTEIN, L., \& COLUCCI, V. M Negative incentive contrast effects with verbal reinforcement. Psychonomic Science, 1970, 18, 318 . 